\title{
Instrument development and application in studies and monitoring of ambient ammonia
}

\author{
Jan Willem Erisman*, Rene Otjes, Arjan Hensen, Piet Jongejan, Pim van den Bulk, \\ Andrey Khlystov, Han Möls, Sjaak Slanina
}

Netherlands Energy Research Foundation, ECN, P.O. Box 1, 1755 ZG Petten, Netherlands

Received 20 December 1999; received in revised form 15 September 2000; accepted 11 November 2000

\begin{abstract}
During recent years, it has become clear that ammonia is an important gas in relation to different environmental issues, such as acidification, eutrophication, human health and climate change (through particle formation). Therefore, there is a growing need to develop and apply instrumentation suitable for research into emission, dispersion, conversion and deposition of ammonia and ammonium. Recently, several instruments were developed suitable for measuring concentrations in ambient conditions even at very low levels, such as ammonia sensors suitable for monitoring and research, deposition measuring systems and aerosol samplers for on-line measurement of aerosol composition. These instruments have been tested and applied in a number of field studies. These studies include dry deposition measurements, ammonium nitrate studies in relation to the (in)direct aerosol effect, emission studies and policy evaluation with concentration and deposition monitoring data. The policy evaluation study showed that the measures to reduce ammonia emissions were not as successful as projected beforehand by statistical studies. (C) 2001 Elsevier Science Ltd. All rights reserved.
\end{abstract}

Keywords: Ammonia; Monitoring; Instruments; Dry deposition; Emission

\section{Introduction}

Recently, assessments and policy development and evaluation is increasingly supported by measurements and monitoring data. The first reason for this is that new environmental pressing issues, such as human health related to particle exposure and climate change related to the (in)direct aerosol effect, ask for new research results. A second reason for this is that the first relatively cheap measures to reduce pollution have been implemented and a stage is reached where the measures become more expensive whereas, the willingness to implement them decreases. In this stage, the demands for proof and thus measurements increases. Furthermore, emission trades will become very important, especially, in relation to

\footnotetext{
* Corresponding author. Tel.: + 31-224-564155; fax: + 31224-563488.

E-mail address: erisman@ecn.nl (J.W. Erisman).
}

joint implementation under the Kyoto protocol. This will induce monitoring programmes to determine the emissions and the changes therein. Another reason for the increasing interest in measurements is the fact that the results of current measures do not give the pollution reductions, which were estimated beforehand. Examples of this is the $\mathrm{NO}_{x}$ emission from traffic which decreased less due to the introduction of the catalyst than estimated as the result of the strong increase in number of cars and traffic intensity. Another example is the decrease in ammonia emissions which should have been $40 \%$ since 1990 but was estimated only about 20\% (Erisman et al., 1998a). These issues make the measurements and monitoring increasingly important. It is therefore necessary to continuously develop specific instruments that fulfil the requirements for different studies and are capable of measuring with the desired accuracy, noise and precision, time resolution and stability.

A variety of ammonia analysers and measuring methods has been developed in the past years (see Mennen et al., 1996, Williams et al., 1992, Allegrini et al., 1991 
and Appel et al., 1988 for overviews). In this paper, we will highlight some recent developments in instrumentation at ECN mainly based on the denuder principle (Ferm, 1979), which have been used in some important issues related to ammonia. Firstly, we will shortly summarise the working, application and performance of new instruments. Secondly, we will show some research results obtained with the instruments. Finally, we will end with some conclusions about the applications and research needs.

\section{Recent instrumental developments}

\subsection{Ammonia concentration monitoring equipment: AMANDA, AiRRmonia and fast sensor}

Two measurement techniques are suitable for concentration monitoring of ammonia, i.e. the AMANDA (ammonia measurement by annular denuder sampling with on-line analyses) and the AiRRmonia. The AMANDA, a rotating wet denuder system was developed already some years ago (Wyers et al., 1993). Ambient air is pumped through an annular denuder using a sample flow of $301 \mathrm{~min}^{-1}$ (Wyers et al., 1993). Ammonia is collected in $9 \mathrm{ml}$ of a $3.6 \mathrm{mM} \mathrm{NaHSO}{ }_{4}$ absorption solution, covering the walls of the annular space in the rotating denuder. Two peristaltic pumps, in counterflow with the sampled air, continuously pump the denuder absorption solution in and out. Downstream the denuder a $0.5 \mathrm{M} \mathrm{NaOH}$ solution, containing $60 \mathrm{ppb} \mathrm{NH}_{4}$ is merged with the absorption solution in a mixing chamber in a debubbler which results in the formation of gaseous ammonia. The solution then passes a semi-permeable PFTE membrane, where approximately $30 \%$ of the ammonia permeate the membrane and are dissolved in a stream of doubledemineralised water and the ammonium concentration is determined conductometrically. The AMANDA system is used in the Netherlands Air Quality Monitoring Network at 8 sites (Buijsman et al., 1998) as a monitoring version, named AMOR, with extensive control options. Some specifications and performances of both instruments are given in Table 1.
The detection limit of the continuous-flow denuder, defined as three times the standard deviation of zero air measurements ( $30 \mathrm{~min}$ averages), is $6 \mathrm{ng} \mathrm{NH} \mathrm{Nm}^{-3}$. The response time of the system was examined by alternately analysing zero air and a test gas mixture containing $3.5 \mu \mathrm{g} \mathrm{NH} \mathrm{NH}_{3} \mathrm{~m}^{-3}$, using a flow rate of the absorption solution of $3.5 \mathrm{ml} \mathrm{min}^{-1}$. After a period of $3.5 \mathrm{~min}$ the instrument has reached $90 \%$ of the response corresponding with the new concentration level. Included in this response time is a constant $2 \mathrm{~min}$ dead time needed for the absorption solution to flow through the denuder into the gas diffusion/conductivity detector. It is therefore possible to resolve rapid fluctuations in the ammonia concentration with a characteristic time down to $1-5 \mathrm{~min}$.

Recently, a new version of the AMANDA called AiRRmonia was developed (http: www.mechatronics.nl/airrmonia_e htm). This monitoring instrument needs less support, less liquids (90\% less) and power and uses a much lower air flow which makes it suitable for other applications (Otjes and Erisman, 1999). The instrument does not use a denuder, but a membrane to select the ammonia from the airflow into de-mineralised water flow. The airflow is about $11 \mathrm{~min}^{-1}$. The detection system of ammonium is similar to that of the AMANDA. Fig. 1 shows a scheme of the AiRRmonia and Table 1 gives some specifications. The performance is comparable to the AMANDA. A special application of the AiRRmonia is the relaxed eddy accumulation, for which a membrane with two compartments was developed (Section 2.2).

The principle of the denuder was used to develop a fast sensor for ammonia. With this instrument ammonia concentrations are measured with a time resolution of $30 \mathrm{~s}$. The denuder is placed in a vertical position and the air stream goes on an opposite direction from the absorption liquid. The detector system is similar to that of the AMANDA but the flows are higher $\left(10 \mathrm{ml} \mathrm{min}^{-1}\right)$. It is not an absolute measurement of the ammonia concentrations. The absolute value has to be determined by regular comparison with an AMANDA. The instrument was developed to measure a down wind cross section of the emission plumes from different sources to determine the source strength. For this, the ammonia sensor is placed on a transport car and pulled across the road through the

Table 1

Performance and specifications of different instruments

\begin{tabular}{lllll}
\hline & Amanda & Amor & AiRRmonia & Fast ammonia sensor \\
\hline Air flow $\left(\mathrm{min}^{-1}\right)$ & 30 & 25 & 1 & 10 \\
Solvent flow $\left(\mathrm{ml} \mathrm{min}^{-1}\right)$ & 1.5 & 1 & 0.1 & 2 \\
Detection limit $\left(\mu \mathrm{g} \mathrm{m}^{-3}\right)$ & 0.01 & 0.01 & 0.1 & 0.5 \\
Accuracy $(\%)$ & 2 & 2 & 3 & - \\
Time resolution $(\mathrm{min})$ & 2 & 3 & 5 & 0.5 \\
\hline
\end{tabular}



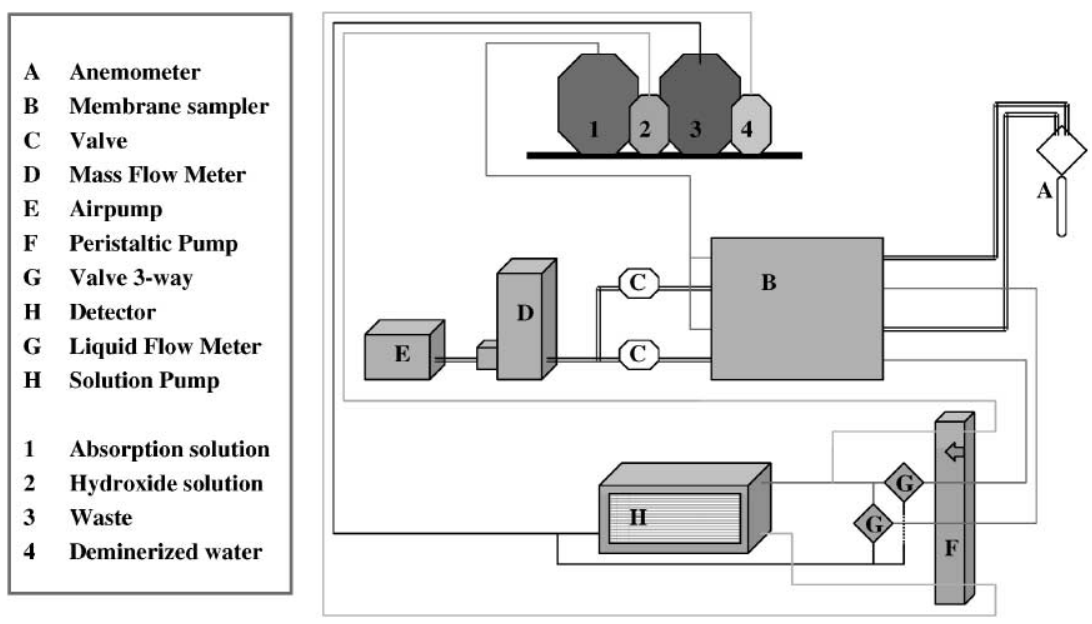

Fig. 1. Scheme of the AiRRmonia instrument suitable for REA measurements.

plumes. The specifications of this instrument are listed in Table 1.

\subsection{Gradient system and $R E A$}

The performance of the AMANDA is suitable for micrometeorological gradient measurements of ammonia to measure its fluxes. Therefore, a gradient system was developed containing three denuders who can be placed at three levels and are connected to one conductivity detector through heated tubes. Together with a sonic anemometer for the measurement of the necessary meteorological parameters, 6 min average ammonia fluxes can be determined. Several studies have been made using the AMANDA gradient system (e.g., Erisman and Wyers, 1993; Sutton et al., 1993; Plantaz, 1998; Wyers and Erisman, 1998).

The most advanced technique, however, to determine trace gas fluxes in turbulent conditions is the Eddy correlation method (e.g., Businger, 1986). The vertical flux can be directly measured in case fast enough sensors (several $\mathrm{Hz}$ ) are available. While the performance of the AMANDA is suitable for micrometeorological gradient measurements vertical wind speed can easily be determined with a high temporal resolution with sonic anemometer, fast sensors for ambient $\mathrm{NH}_{3}-$ concentration measurements are not yet available. The relaxed eddy accumulation technique (REA) overcomes the need of a fast concentration measurement by sampling gases at a constant rate during up and down droughts which are fed to separate reservoirs during the measurement period (Businger and Oncley, 1990). The flux is then provided as

$F=\alpha \sigma_{\mathrm{w}}\left(c_{\text {up }}-c_{\text {down }}\right)$ with an integration time period between 10 and $120 \mathrm{~min}$. Here $\sigma_{\mathrm{w}}$ is the standard deviation of the vertical wind speed, c is the concentration. The coefficient $a$ has been determined from eddy correlation measurements to be around 0.6. REA measurements have been proved by several groups to be a sound method for $\mathrm{CO}_{2}$ flux measurements through comparison with the eddy correlation technique (a.o. Hensen et al., 1996). So far, the REA technique has not been proofed to be a sound method for $\mathrm{NH}_{3}$ flux measurements. ECN developed a $\mathrm{NH}_{3}$-REA system based on the AiRRmonia system. The REA system consists of a membrane sampler with two chambers to sample the upward and downward airflow concentrations (Fig. 1). The system measures air split into up and down drafts over $10 \mathrm{~min}$. After $10 \mathrm{~min}$, the ammonia concentration is detected in sequence by the same detector. Therefore, the net-flux is the difference between the $10 \mathrm{~min}$ up and next $10 \mathrm{~min}$ down flux, etc.

\subsection{Continuous ammonium aerosol measurements}

The steamjet aerosol collector (Sjac) was developed to continuously measure aerosol concentrations (Khlystov et al., 1995). An air stream free of water-soluble gases is rapidly mixed with steam. The resulting supersaturation causes aerosol particles to grow into droplets. The droplets containing dissolved aerosol species are then collected by two cyclones in series. The solution collected in the cyclones is constantly pumped out and can be on- or off-line analysed by means of ion chromatography or flow injection analysis. On the basis of the new sampling principle, an aerosol sampler was designed which is capable of continuously sampling particles quantitatively down to several nanometers in diameter. The masssampling efficiency of the instrument was found to be 
99\%. The detection limit of the sampler for ammonium, sulphate, nitrate and chloride ions is below $0.7 \mu \mathrm{g} \mathrm{m}^{-3}$. During measurements the sampler proved to be stable, working without any assistance for several months in a row with maintenance every week.

\section{Ammonia research and policy evaluation}

\subsection{Ammonia network}

In order to evaluate the ammonia policy a network of eight $\mathrm{NH}_{3}$ stations in the Netherlands equipped with the AMORs was installed in 1992 (Buijsman et al., 1998). The measurement locations are shown in Fig. 2, together with the emission distribution of ammonia on a $5 \times 5 \mathrm{~km}$ grid. It is impossible to obtain a regional distribution of the ammonia concentrations in the Netherlands only with measurements because of the large number of sources and the large horizontal and vertical gradients in concentration. The sites were therefore chosen as to cover the Netherlands, but also to cover three different emission areas: (i) three intensive livestock breeding areas dominated by chicken breeding, pigs or cattle; (ii) two grassland areas with mainly dairy farms and intermediate emissions and (iii) three background areas.

The results of the data show that the average diurnal pattern for the different locations is different according to the nature of the emission area (Fig. 3). The sites located in the high emission areas: Vredepeel, Wekerom and Eibergen show a distinct minimum during daytime and highest values in the early morning, whereas the sites

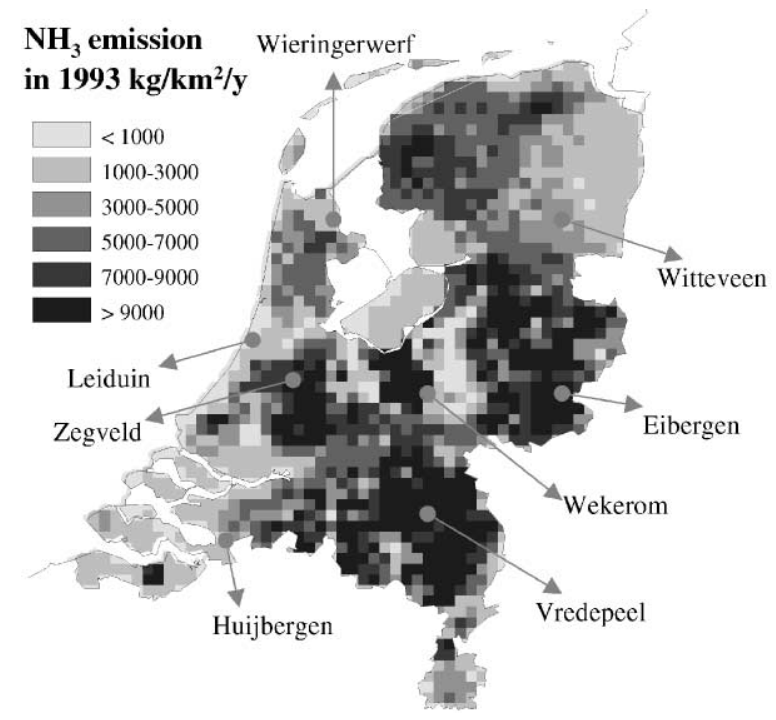

Fig. 2. Total $\mathrm{NH}_{3}$ emission in the Netherlands in 1993 and the $\mathrm{NH}_{3}$ concentration network sites. located in the background areas, Leiduin and Huijbergen show a distinct maximum during the day time. The intermediate sites generally show a small minimum. The reason for this difference in diurnal variation is the fact that in high emission areas there is a build up of concentration during the stable conditions at night, which is dispersed again at day-break when the turbulence increases. At the background sites the stable conditions at night prevent the long-range transport needed to increase the concentration, whereas at daytime this transport dominates the concentration levels.

It is questionable if continuous monitoring of hourly values is necessary and what the influence on the annual average concentration is in case of loss of data e.g. due to technical failure. One year of hourly data at a background station and a station in a high-emission area were selected to determine the influence of loss of monitoring data. Randomly, a certain percentage of the hourly data (total 8736) was left out from the one-year database and the remaining data were used to calculate the annual average. Furthermore, it was determined what the influence is of rejecting several days of data in a row. This option was selected because the annual average concentration is determined to a large extend by peak values after spreading of manure which show increased emissions in periods of 3-7 days. Finally, it was determined what the influence is of rejecting months of data. The results are presented in Table 2. It is remarkable that an appreciable loss of data can be tolerated before the uncertainty in annual average concentrations becomes higher than $10 \%$. Loss of days of data does not lead to serious errors as long as half of the month's data is available. When whole months of data are lost, serious deviations from the true annual mean can be seen after three months. This has to do with the monthly variation in concentration, with a clear early spring maximum due to the regulations that does not allow manure application in winter. Study of the phenomenology of the ammonia concentrations lead to insight in the emissions, transport in conversion processes needed for a thorough understanding of the behaviour of ammonia and its effects (e.g., Aben et al., 1995; Erisman and Bleeker, 1997; Buijsman et al., 1998).

\subsection{Continuous dry deposition measurements}

One way to directly monitor the effect of regulations to reduce emissions is the continuous measurement of the dry deposition. Ideally, this should be done with micrometeorological methods because they measure the net flux to or from the whole system, without manipulating or disturbing the system. At Speulder forest, which is located in the centre of the largest nature area in the Netherlands, the AMANDA gradient system was implemented at the end of 1992. Since then continuous measurements of the vertical concentration gradient at 


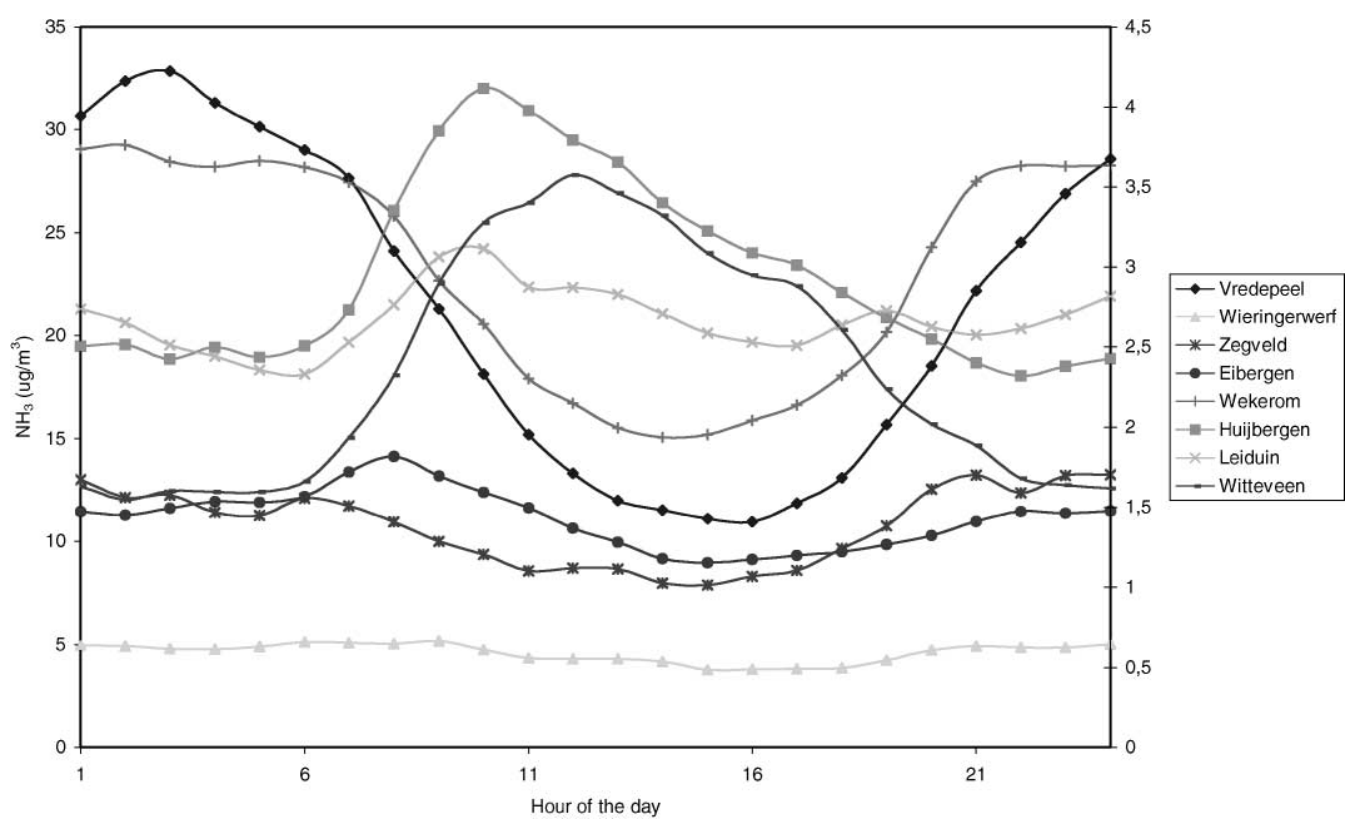

Fig. 3. Diurnal variations of the concentrations at the 8 monitoring sites in 1993 (data from the National Institute of Public Health and Environment, RIVM, the Netherlands). Wieringerwerf, Huijbergen, Leiduin and Witteveen are represented by the right axis.

Table 2

The comparison of annual average ammonia concentrations at two sites after rejection of data

\begin{tabular}{|c|c|c|}
\hline Rejection of data & $\begin{array}{l}\text { Vredepeel (high emission) } \\
\% \text { different from average }\end{array}$ & $\begin{array}{l}\text { Huijbergen (background) } \\
\% \text { different from average }\end{array}$ \\
\hline $10 \%$ random & 0.2 & -0.3 \\
\hline $30 \%$ random & -0.9 & -0.2 \\
\hline $50 \%$ random & 0.4 & -0.8 \\
\hline $70 \%$ random & -1.3 & -1.3 \\
\hline $90 \%$ random & -2.8 & -2.2 \\
\hline 1 day of each month & -0.4 & -0.2 \\
\hline First 7 days of each month & 0.7 & 4.8 \\
\hline First 14 days of each month & 1.7 & -3.0 \\
\hline First 21 days of each month & 1.6 & -11.7 \\
\hline 1 month & 3.8 & 1.4 \\
\hline First two months & 6.9 & 4.7 \\
\hline First five months & -5.0 & -21.8 \\
\hline First eight months & -21.4 & -32.6 \\
\hline
\end{tabular}

three heights are available, which, together with the meteorological parameters measured with a sonic anemometer and some additional sensors enable to estimate the dry deposition (Wyers and Erisman, 1998). Five years of data have been processed and the annual variation established. Fluxes are only valid under stationary conditions, which are not always met (Businger, 1986). Selection criteria were derived to select the measurements under well-defined conditions. These selections include wind direction, wind speed, error in concentration and rapid changing conditions (e.g., Wyers and Erisman, 1998; Erisman et al., 1994). A procedure was developed to obtain monthly or annual data from the selected measurements (Erisman et al., 1998b). Fluxes were calculated for the selected data, whereas for the rejected data fluxes were estimated with the inferential technique 


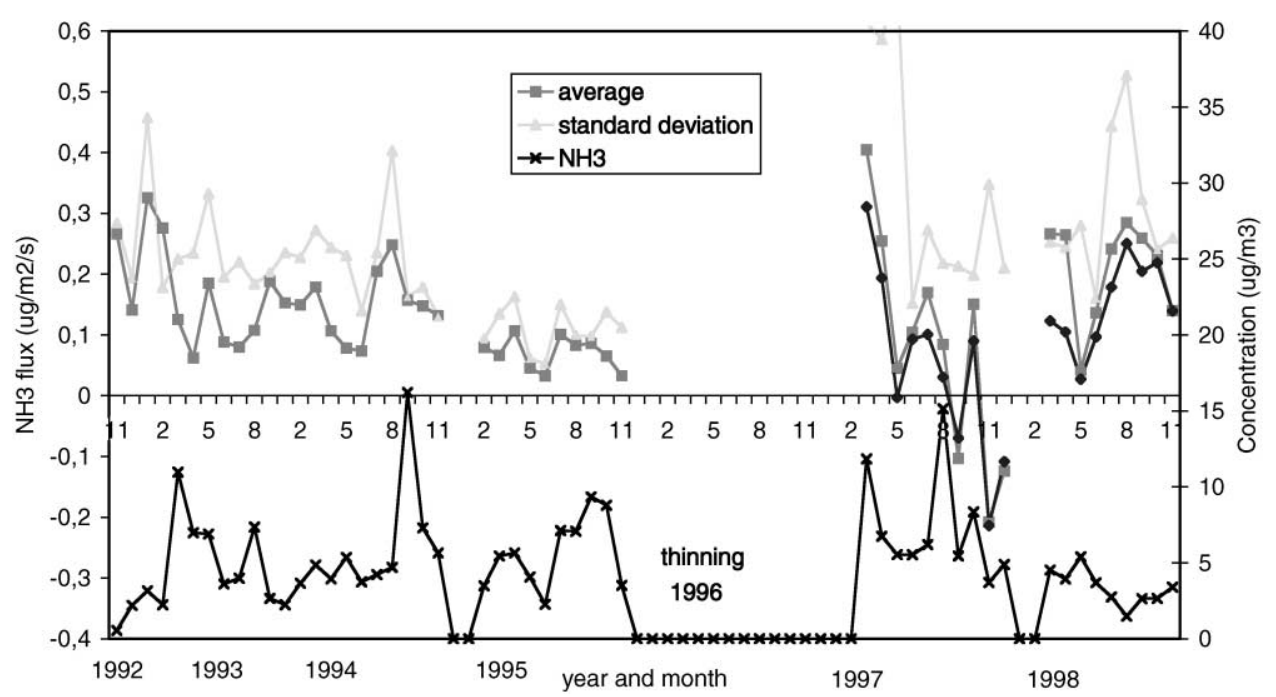

Fig. 4. Monthly average fluxes of $\mathrm{NH}_{3}$, its standard deviation $\left(\mu \mathrm{g} \mathrm{m}^{-2} \mathrm{~s}^{-1}\right)$ and the monthly average $\mathrm{NH}_{3}$ concentration $\left(\mu \mathrm{g} \mathrm{m}^{-3}\right)$ measured between 1993 and 1998.

using surface resistance parameterisations derived from the selected dataset. Fig. 4 shows the monthly average fluxes the standard deviation therein and the monthly $\mathrm{NH}_{3}$ concentration at Speulder forest between 1993 and 1998. At the end of 1995, the measurements had to stop because of the thinning of the forest. The measurements started again at the beginning of 1997. Results show a small decrease of the flux from the end of 1992 until the end of 1995. The fluxes in 1997 and 1998 are at the same level again of 1992, but much more variable. The standard deviation is much higher, mainly because of a lot more technical failure, especially in 1997 leading to much less hourly data. The difference between 1997/1998 and the years before might also be the result of the thinning. Before the thinning the leaf area index was 22 , which was much less after thinning. The trees have grown much after the thinning: the top of most of the trees is at the same level as the lower measuring point. This makes the interpretation of the monthly values very difficult. A more thorough study has to provide a more detailed interpretation of the monthly variation.

\subsubsection{REA intercomparison}

In September 1998 an intercomparison experiment was organised at Schagerbrug, a managed grassland in the North of the Netherlands. Two REA systems for $\mathrm{NH}_{3}$, one from ECN and the other from IUL (Switzerland) were compared to the AMANDA gradient system. There are big differences between the hourly average values measured with the different systems, even when very strict selections are made in concentrations and meteorological conditions. If moving averages of thirty 10 min fluxes are compared the agreement improves (see
Fig. 5). There were several reasons for the big discrepancies: the unfavourable conditions (wet, low concentrations, the wrong time delay, which was used by the gradient systems affecting the difference between the different levels, rapidly changing conditions, etc.), the long inlet tubes of $1.5 \mathrm{~m}$ used for the ECN REA system and the fact that it was the first test outside. The agreement between the gradient system and IUL REA system is also rather poor, mainly because of the same reasons. This intercomparison shows the state of development of REA $\mathrm{NH}_{3}$ measurements, which clearly need further improvement.

\subsection{Sjac application for $\mathrm{NH}_{4} \mathrm{NO}_{3}$ studies in relation to aerosols and climate}

Ammonium nitrate appears to play an important role in atmospheric chemistry, in the background particulate matter concentrations and in relation to climate change. Its role in atmospheric chemistry is important because it determines the sink strength of $\mathrm{HNO}_{3}$ and $\mathrm{NH}_{3}$ and therewith influences the transport distances of these gases (aerosols are transported much further away because of their relatively low dry deposition velocity compared to the gases). Once the aerosols are formed, they contribute to the background particulate matter $\left(\mathrm{PM}_{2.5}\right.$ and $\left.\mathrm{PM}_{10}\right)$ concentrations affecting human health through respiratory effects (o.a. Watson, 1997). Aerosols can have a direct and indirect (through cloud formation) cooling effect. Until now, only sulphate aerosols have been considered in the global change discussion, because nitrate was believed to be present in largest sizes and therewith having 


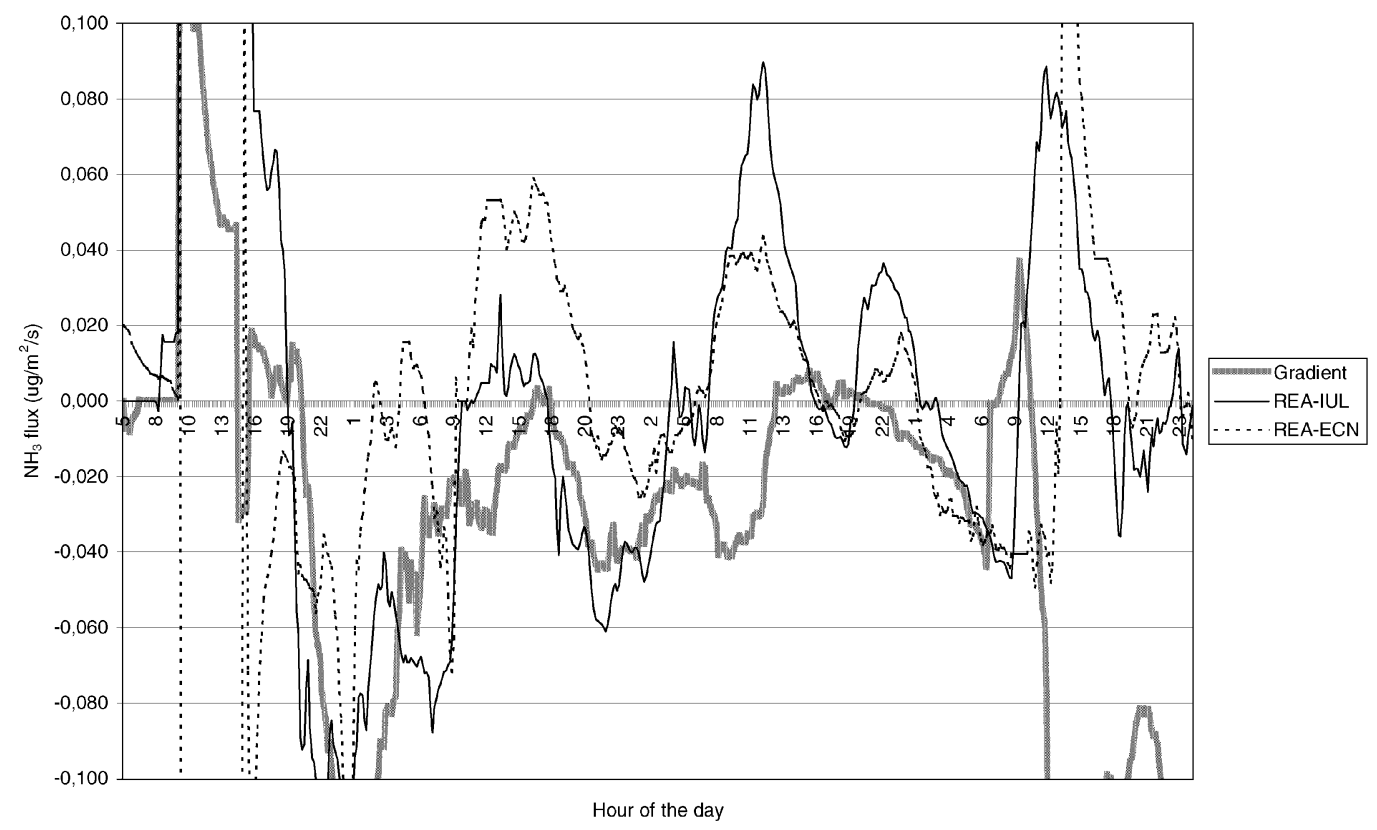

Fig. 5. Comparison of ammonia fluxes (moving averages of thirty 10 min values) measured with two REA systems and a gradient system.

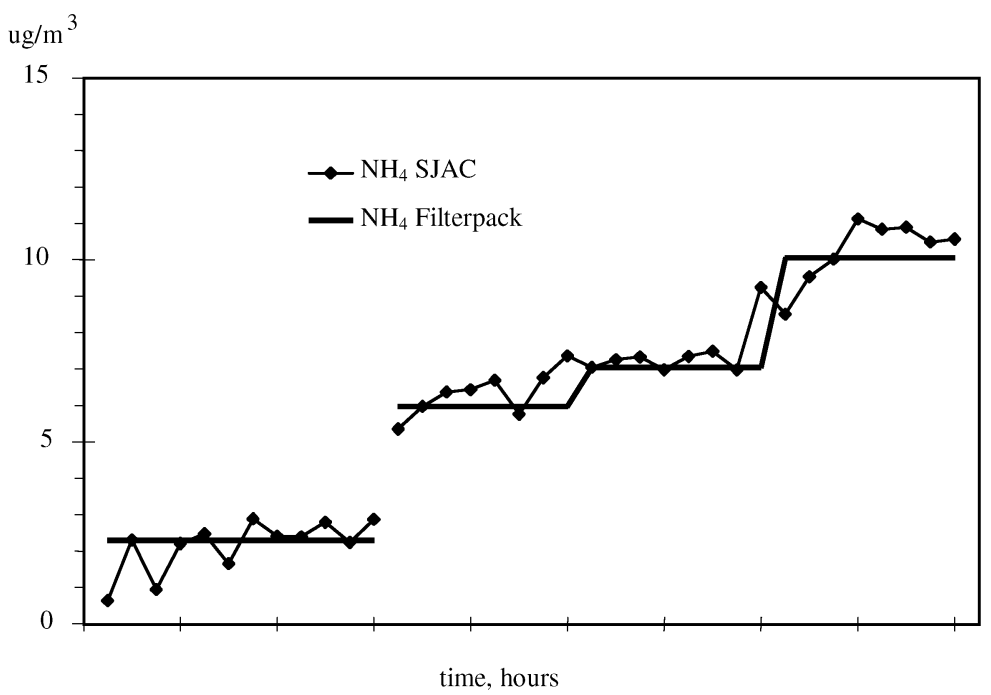

Fig. 6. Comparison of Sjac ammonium concentrations with filter pack measurements.

less influence on the radiation balance (IPCC, 1995). Recently, nitrate was determined to have the same cooling potential as sulphate (e.g., Khlystov, 1998). One of the main problems with measuring ammonium nitrate aerosol concentrations is the appreciable loss because of evaporation that occurs using filter packs and regularly used sampling equipment (Khlystov, 1998). Concentration measurements made up to now, therefore, underesti- mate the actual concentrations. Another problem up to now was the lack of continuous sampling devices hampering process studies on aerosol formation and evaporation or conversion. The Sjac system has been tested with artificially generated aerosol concentrations and by well-handled filter-pack methods. If well handled and analysed directly after sampling filter-packs can serve as a reference method. Fig. 6 shows an example of such 
a comparison. The Sjac system was used to continuously measure the aerosol composition at ECN in Petten for several months, showing that the aerosol nitrate concentrations with a peak around $1 \mu \mathrm{m}$ are as large as the sulphate concentrations (Khlystov, 1998).

\subsection{Emission research}

The gap between emission estimates and measured ambient levels of ammonia, which has been demonstrated by Erisman et al. (1998a) based on the network data from Section 3.1 has to be explained in order to improve the effect of the regulations. Several hypotheses were given which might explain the gap (see Erisman and Monteny, 1998, for a review). Two of these hypotheses were the long-term emissions after injection of manure in grassland and the uncertainty in measurement techniques used to determine the effect of injection techniques on the emissions. In order to quantify these hypotheses, a programme was run to determine the emission reduction due to injection of manure in grassland relative to surface spreading. One of the aims of the study, was to evaluate the long-term behaviour of emissions from grassland. For this, a new measuring method was developed the static plume dispersion method in combination with the fast response method. These methods provide continuous data with a high time resolution. Both methods determine the $\mathrm{NH}_{3}$ concentration in the horizontal cross-section of the plumes. The so-called fast response sensor (see Section 2.1) was transported back and forth through the plumes and three continuous $\mathrm{NH}_{3}$ monitors (AMANDA) were located at fixed positions down wind of each plot. The fast response sensor gives detailed information on the shape of the whole $\mathrm{NH}_{3}$ plume (Fig. 7). The fixed monitors only give 3 points in the plume and an interpolation is needed to obtain the complete plume shape. The fast response data is used as a reference to check these interpolations. The concentration measurements at the fixed locations provide a time series of the emission level for periods with wind coming over the manure plots. By measuring the cross-section of the plume, combined with meteorological parameters the emission can be calculated using a dispersion model as illustrated in Fig. 7.

The model used was the so-called SLAM model (Short-term Local scale Ammonia transport Model, Boermans and van Pul, 1993). The first $3 \mathrm{~h}$ after manure spreading the fast response method was used for calculating the emissions, because of saturation of the AMANDA's. About $3 \mathrm{~h}$ after manure spreading the emission estimated obtained from the static plume dispersion method can be used as well. The continuous registration of the $\mathrm{NH}_{3}$ concentrations enables study of the process of emission that takes place and the influence of meteorological conditions on the emission. In Fig. 8 the simultaneous emissions are plotted together with wind speed and rainfall data. Unfortunately, rainfall data was only available during the first week of the experiments. The results show that the emission strongly depends on wind speed and that rainfall can increase the emissions and that even after two weeks a small net emission is measured from the plots. The fluxes are, however, too small to support the hypothesis that the difference between the estimated Dutch emissions and those derived from measurements can be explained by long-term (small) emissions after incorporation of manure into the soil.

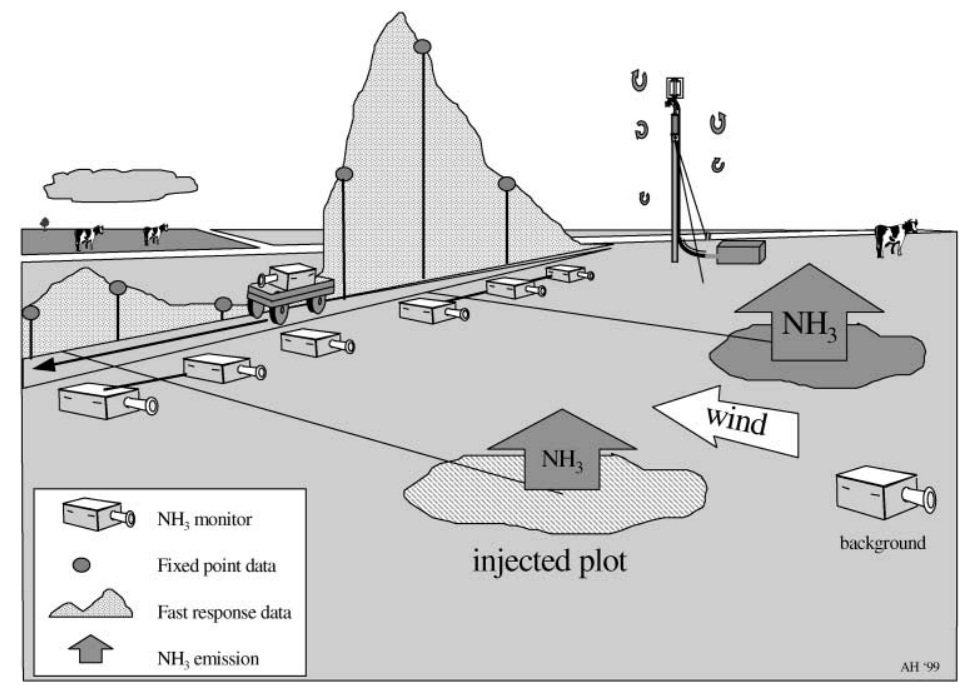

Fig. 7. Illustration of the methods to calculate emissions from plume dispersion measurements. 


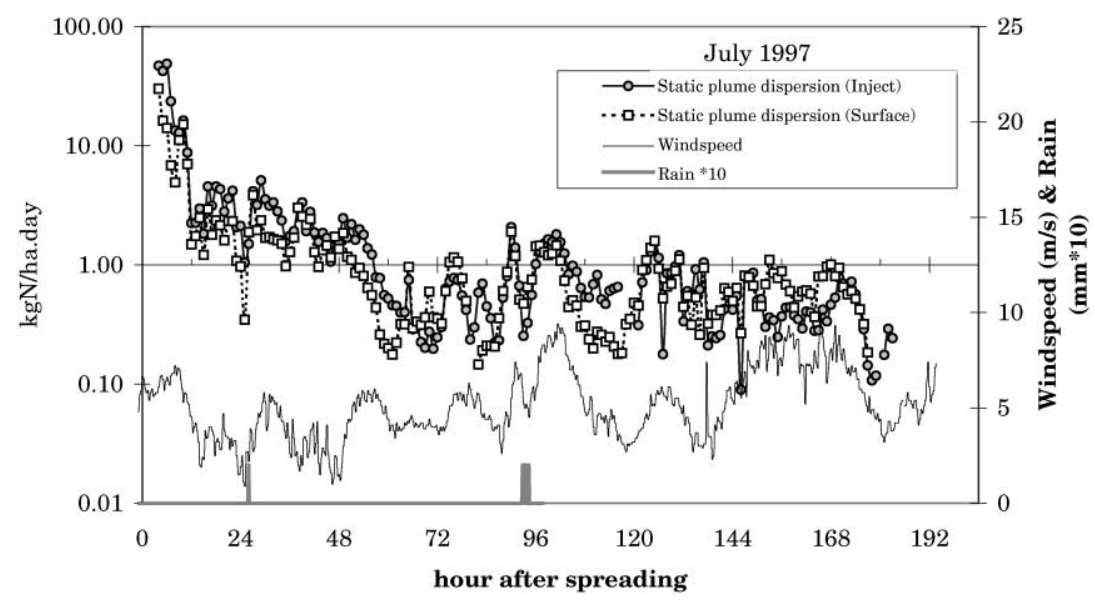

Fig. 8. Emission levels obtained with the static plume dispersion method plotted together with windspeed and rainfall data.

\section{Conclusions/synthesis}

Ammonia plays a very important role in many environmental issues. These include a.o. acidification, eutrophication, exposure of humans to particles, the cooling effect of aerosols and the long-range transport of $\mathrm{S}$ and $\mathrm{N}$. It is therefore needed to develop instruments for different studies and applications. Instrument development serves several goals:

- process studies,

- monitoring of policy development: trend studies,

- estimation and evaluation of emissions.

The past years a whole 'family' of instruments was developed at ECN based on the continuous absorption of ammonia in de-ionised water, by using a rotating denuder and recently by using membranes. The performance of the instruments is very good. However, maintenance under field conditions sometimes is more than can be expected of monitoring equipment, especially under freezing conditions. Recent studies on the effectiveness of ammonia abatement show that the measures taken in the Netherlands to reduce $\mathrm{NH}_{3}$ emissions have so far not resulted in the estimated decrease in emissions. This conclusion is based on an analysis of $\mathrm{NH}_{3}$ and $\mathrm{NH}_{4}$ monitoring data in a network. This reflects the importance of measurements and the necessary instrumentation. This evaluation is the end product of instrumental development and its application in process studies, such as deposition studies, studies on the conversion rate of ammonia to ammonium and studies on the ammonia emissions. The current problems we face ask for further development, especially in the direction of more simple and direct surface exchange (emission/deposition) measurements of $\mathrm{NH}_{3}$, concentration monitoring of $\mathrm{NH}_{4}^{+}$and instruments to be used for particle dry deposition.

\section{Acknowledgements}

Albrecht Neftel and Andreas Blatter (IUL) for the REA measurements at Schagerbrug. R\&R Mechatronics is acknowledged for their contribution to the development of the AiRRmonia system.

\section{References}

Aben, J.M.M., Heuberger, P.S.C., Acharya, R.C., Dekkers, A.L.M., 1995. Preliminary validation of ammonia emission data using a combination of monitoring and modelling. In: Heij, G.J., Erisman, J.W. (Eds.), Acidification; Do we have enough answers? Studies in Environmental Science 64. Elsevier, Amsterdam, pp. 81-90.

Appel, B.R., Tokiwa, Y., Kothny, E.L., Wu, R., Povard, V., 1988. Evaluation of procedures for measuring atmospheric nitric acid and ammonia. Atmospheric Environment 22, 1565-1573.

Boermans, G.M.F., Pul, W.A.J. van, 1993. SLAM, een transportmodel voor de korte termijn en de korte afstand met als toepassing de beschrijving van de verspreiding van ammoniak. Report No. 222105003, National Institute of Public Health and Environmental Protection (RIVM), Bilthoven, The Netherlands.

Buijsman, E., Aaben, J.M.M., Elzakker, B.G.van., Mennen, M.G., 1998. An automatic atmospheric ammonia network in The Netherlands: set up and results. Atmospheric Environment 32, 317-324.

Businger, J.A., 1986. Evaluation of the accuracy with which dry deposition can be measured with current micrometeorological techniques. Journal of Climate and Applied Meteorology $25,1100-1124$. 
Businger, J.A., Oncley, S.P., 1990. Flux measurements with conditional sampling. Journal of Atmospheric and Oceanic Technology 7, 349-352.

Erisman, J.W., Vermetten, A.W.M., Asman, W.A.H., Slanina, J., Waijers-Ijpelaan, A., 1988. Vertical distribution of gases and aerosols: the behaviour of ammonia and related components in the lower atmosphere. Atmospheric Environment 22, $1153-1160$.

Erisman, J.W., Wyers, G.P., 1993. Continuous measurements of surface-exchange of $\mathrm{SO}_{2}$ and $\mathrm{NH}_{3}$ : implications for their possible interactions in the deposition process. Atmospheric Environment 27A, 1153-1161.

Erisman, J.W., Elzakker, B.G.van, Mennen, M.G., Hogenkamp, J., Zwart, E., Beld, L.van.den., Römer, F.G., Bobbink, R., Heil, G., Raessen, M., Duyzer, J.H., Verhage, H., Wyers, G.P., Otjes, R.P., Möls, J.J., 1994. The Elspeetsche Veld experiment on surface exchange of trace gases: summary of results. Atmospheric Environment 28, 487-496.

Erisman, J.W., Bleeker, A., 1997. Emission, concentration and deposition of acidifying substances. In: Heij, G.J., Erisman, J.W. (Eds.), Acid Atmospheric Deposition and its Effects On Terrestrial Ecosystems in The Netherlands. Studies in Environmental Sciences 69. Elsevier, Amsterdam, pp. 21-82.

Erisman, J.W., Bleeker, A., Jaarsveld, van J.A., 1998a. Evaluation of the effectiveness of the ammonia policy using measurements and model results. Environmental Pollution 102, 269-274.

Erisman, J.W., Mennen, M.G., Fowler, D., Flechard, C.R., Spindler, G., Grüner, A., Duyzer, J.H., Ruigrok, W., en Wyers, G.P., 1998b. Deposition monitoring in Europe. Environment Monitering and Assessment 53, 279-295.

Erisman, J.W., Monteny, G.J., 1998. Consequences of new scientific findings for future abatement of ammonia emissions. Environmental Pollution 102, 275-282.

Ferm, M., 1979. Method for determination of atmospheric ammonia. Atmospheric Environment 13, 1385-1393.

Hensen, A., Vermeulen, Wyers, G.P., Zhang, Y., 1996. Eddy correlation and relaxed eddy accumulation measurements of $\mathrm{CO}_{2}$ fluxes over grassland. Physics and Chemistry of the Earth 21, 383-388.
IPCC, 1995. The Science of Climate Change. Cambridge University Press, Cambridge.

Khlystov, A., Wyers, G.P., Slanina, J., 1995. The steam-jet aerosol collector. Atmospheric Environment 29, 2229-2234.

Khlystov, A., 1998. Cloud forming properties of ambient aerosol in The Netherlands and resultant shortwave radiative forcing of climate. Ph.D. Thesis, Wageningen University, The Netherlands.

Mennen, M.G., Elzakker, B.G.van, Putten, E.M.van, Uiterwijk, J.W., Regts, T.A., Hellemond, J.van, Wyers, G.P., Otjes, R.P., Verhage, A.J.L., Wouters, L.W., Heffels, C.J.G., Romer, F.G., van den Beld, L.vanden., Tetteroo, J.E.H., 1996. Evaluation of automatic ammonia monitors for application in an air quality monitoring network. Atmospheric Environment 30, 3239-3256.

Otjes, R.P., Erisman, J.W., 1999. Haalbaarheidstudie miniaturisering ammoniak analyser (Feasibility study on the diminution of ammonia analyser). Report ECN-CX-99-015, ECN, Petten, the Netherlands (in Dutch).

Plantaz, M., 1998. Surface/atmosphere exchange of ammonia over grazed pasture. Ph.D. Thesis, University of Wageningen, Wageningen, the Netherlands.

Sutton, M.A., Pitcairn, C.E.R., Fowler, D., 1993. The exchange of ammonia between the atmosphere and plant communities. Advances in Ecological Research 24, 301-393.

Watson, J.G., 1997. Ambient particles and health: lines that divide. Journal of Air and Waste Management Association 47, 995-1008.

Williams, E.J., Sandholm, T.S., Bradshaw, J.D., Schendel, J.S., Langford, A.O., Quinn, P.K., LeBel, P.J., Vay, S.A., Roberts, P.D., Norton, R.B., Watkins, B.A., Buhr, M.P., Parrish, D.D., Calvert, J.G., Fehsenfeld, F.C., 1992. An intercomparison of five ammonia measurement techniques. Journal of Geophysical Research D 97, 11591-11611.

Wyers, G.P., Otjes, R.P., Slanina, J., 1993. A continuous-flow denuder for the measurement of ambient concentrations and surface exchange fluxes of ammonia. Atmospheric Environment 27A, 2085-2090.

Wyers, G.P., Erisman, J.W., 1998. Ammonia exchange over coniferous forest. Atmospheric Environment 32, 441-452. 